\title{
Effects of Exposure to Electromagnetic Field on Some Hematological Parameters in Mice
}

\author{
Mariam S. Alghamdi ${ }^{1}$, Nawal A. El-Ghazaly ${ }^{2}$ \\ ${ }^{1}$ Sciences Faculty for Girl, Department of Zoology, King Abdulaziz University, Jeddah, KSA \\ ${ }^{2}$ Department of Science, Alexandria University, Alexandria, Egypt \\ Email: gibriel2003@gmail.com
}

Received March 1, 2012; revised April 5, 2012; accepted April 14, 2012

\begin{abstract}
Objective: To investigate the effects of electromagnetic fields on some hematological parameters of Male white mice. Methods: In this study two experiments were used as short-term and long-term experiments. Short-term experiments were carried out in 80 male white Balb/c mice exposed to two types of mobile phone for a period time up to $60 \mathrm{~min}$ a day for 2 weeks. Long-term experiments were carried out in 30 male white Balb/c mice exposed to two types of mobile phone for a period time up to $90 \mathrm{~min}$ a day for a month, two months, three months. Result: The present result found that a decline in hemoglobin, hematocrit, red blood cells count, in addition to the platelets count after short and long exposure to both types of mobile phone (Alcatel, Nokia). It was observed that the average number of white cells and lymphocytes increased significantly, indicating the increase to the body's immune response to radiation. Also, when exposed to both devices (Alcatel, Nokia) for 15 minutes, the red blood cells began to take a role of formation due to an increase in the viscosity of the blood and the ability of the cells adhesion. Increased duration of exposure to 30-minute to both devices revealed disparities in the sizes of red blood cells with the appearance of a large proportion of cells with pale colors due to lack of hemoglobin. In the group exposed for 45 minutes showed clearly the influence of mobile phones on examining blood smears which observed a proportion variation in the cell sizes with the emergence of forms of abnormal forms, including pellets cleft with many areas empty of red blood cells, With increasing in of exposure duration to 60 minutes, red blood cells appeared completely different from the natural form and took the forms resembling the eye and tear that appear in the case of anemia. After three months of exposure to both types of mobile phone showed pathological changes in red blood cells where gripped the outer membrane of the red corpuscle changes and become serrated. Conclusion: Exposure to electromagnetic fields is responsible for the variations of some hematological parameters in rats.
\end{abstract}

Keywords: Component; White Blood Cells (WBC); Male White Balb/C Mice Strain; Complete Blood Count; Platelets (PLT) Count

\section{Introduction}

Electromagnetic hazarded was considered one of the most dangerous types of pollution [1] due to the electromagnetic fields which affected the functions of cells of the body [2]. The potential health risks of radiofrequency electromagnetic fields (RF EMFs) emitted by mobile phones are currently of considerable public interest [3]. Electromagnetic waves occur imbalance in the cell power which disturbed their function. This disturbance induced according to the severity of the disorder and the damage induced [1]. It is known from the magneto-hydrodynamics that when a stationary, transverse magnetic field is applied externally to a moving electrically conducting fluid, electrical currents are induced in the fluid. The interaction induced currents and the applied magnetic field produces a body forces (Lorentz force) which tends to retard the movement of blood [4]. The main sources of electromagnetic field are electromagnetic devices as mobile phones, electrical and wireless devices.

The mobile phone considered of the most import technology, together with a growing number of cellular telephone users increases the interest in the effect of electromagnetic fields (EMF) emitted by them on live organisms [5]. According to global statistics, the steady increase in the use of mobile phones has increased the establishment of ground stations required [6]. Many studies reported that radiation from mobile phones absorbed by the human body and turn inside to heat. This biological effect leads to the continuation of the existence of many damage risks caused to human and their vital organs. This findings have confirmed the report of the Australian Radiation Protection in (2005) where $70 \%$ of the waves emitted by mobile phonies absorbed in the user's head 
which leads to increase the speed of nerve impulses, blood pressure and heart rate that exposure to electromagnetic waves leads to an imbalance in the circulatory system, increase in blood flow and disruption in blood pressure $[7,8]$ and decrease in the hemoglobin [9] increased the incidence of leukemia in children [10-12] and changes in cerebral blood barrier [13]. Liu et al. [14], Mandal [15], Bali \& Awasthi [16] and Varshney et al. [17] studied the pulsatile blood flow in the artery having single mild stenosis. Kuipers et al. [18] studied the influence of static magnetic fields on cardiovascular and sympathetic function. Djeridane et al. [3] studied the influence of electromagnetic fields emitted by GSM-900 cellular telephones on the circadian patterns of gonadal, adrenal and pituitary hormones in men.

Blood is the only tissue that flows throughout your body. This red liquid carries oxygen and nutrients to all parts of the body and waste products back to your lungs, kidneys and liver for disposal. It is also an essential part of your immune system, crucial to fluid and temperature balance, a hydraulic fluid for certain functions and a highway for hormonal messages [17]. The effects of the interaction between a magnetic field and the haemodynamics of the arterial system have been studied by Sud and Sekhon [4]. They found that the method requires the derivation of an expression of the conductance of a single artery in the presence of a transverse magnetic field.

The aim of the present study was to investigate the influence of electromagnetic fields on blood profile of Balb/c mice using two mobile phones of Global System for Mobile Communication (GSM).

\section{Material and Methods}

\subsection{Experimental Animals}

Male white Balb/c mice strain (Plan experience based on single-sex only and was chosen for the sensitivity of male reproductive organ) were used in this experiment, these mice's were obtained from the animal house at King Fahd Medical Research, University of King Abdul Aziz, Saudi Arabia.

\subsection{Devices Used in the Experiments (Mobile Phones)}

Two different types of mobile phones were used in this experiment based on the value of the different specific absorption coefficient (SAC) to them. The mobile phone Alcatel: Certified to work on Global System for Mobile Communication (GSM) frequency 900 - 1800 MHZ The highest SAC value is $0.49 \mathrm{~W} / \mathrm{kg}$. The mobile phone Nokia: Certified to work on the system (GSM) frequency $900-1800 \mathrm{MHZ}$ The highest SAC value is $0.72 \mathrm{~W} / \mathrm{kg}$.

\subsection{Experimental Design}

In this study two experiments were used as short-term and long-term experiments.

\subsubsection{Short-Term Experiment}

Eighty male white Balb/c mice were used their age 6 week and with weights ranged between 17 - $18 \mathrm{gm}$. They were divided into 2 main groups, each under the impact of different kind of mobile phones. Mice were exposed in a cage fixed to the rays of the mobile phone at the same time and thus will be exposed mice equal amounts of radiation were installed temperature and humidity throughout the duration of experiment

Each group was divided into four major sub-groups ten rats each in separate cages as follows:

Sub-group I: exposed to mobile phone for a period of time 15 minutes a day for two weeks. Sub-Group II: exposed to mobile phone for a period of time 30 minutes a day for two weeks. Sub-Group III: exposed to mobile phone for a period of time 45 minutes a day for two weeks. Sub-Group IV: exposed to mobile phone for a period of time 60 minutes a day for two weeks.

Mobile phone was hold inside the breeding cages with a quantity of proper food and water. For the movement of animals were within the scope of the cage and is a natural way in the non-exposure periods do not think it has a large impact on patients mice compared to radiation

\subsubsection{Long-Term Experiment}

In this experiment 30 mice from the age of weaning (3 weeks), to reach the end of the experiment to the age of 15 weeks. Three groups 10 each were used Groups 1 and 2 exposed mice to two types of mobile phone (Alcatel and Nokia) separately, for a period time up to 90 minutes a day for a month, two months, three months. While group 3 were control without exposed to any mobile devices. After the end of the experiment blood and statistical studies were done.

\subsection{Hematological Studies}

\subsubsection{Collection of Blood Samples}

Blood samples were taken at the end of short and long experiments. The blood samples were collected on heparin anti-clotting, and these samples were used in assessment [19] of blood profile:

Complete blood count, [20] including red blood cells count, hemoglobin $(\mathrm{Hb})$ and hematocrit (Hct). Measurements of RBC Indices [20] are mean cell volume (MCV), mean corpuscular haemoglobin (MCH) and mean corpuscular haemoglobin concentration (MCHC), white blood cells (WBC), platelets (PLT) count.

\subsubsection{Preparation of Blood Smear and Staining}

Blood smears were done and stained with Giemsa Stain then treated with Zaylol and embedded in Canada balsam [21,22]. 


\subsection{Statistical Analysis}

The results obtained in the present work are represented as means \pm standard error, and were analyzed using analysis of variance (ANOVA). The significance of difference between means at $\mathrm{P}<0.05$ was calculated using the Duncan Multiple Range Test [23].

\section{Results}

It was observed from the results of the readings recorded in Table 1 that the rate of hemoglobin was $14.36 \pm 0.86$ $\mathrm{g} / \mathrm{dL}$, when exposed for 15 minutes to Alcatel mobile phone, then began to decline after exposure time reached 30 minutes to $13.62 \pm 0.81 \mathrm{~g} / \mathrm{dL}$ and was $12.86 \pm 0.43$ $\mathrm{g} / \mathrm{dL}$ when exposed for 45 minutes and then showed its lowest value at 60 minutes after exposure time with rate reached $11.92 \pm 0.23 \mathrm{~g} / \mathrm{dL}$. The results of long term experiment (post 3 months) were illustrated in Table 2 which showed the hematological parameters of the exposed mice for three months to two different types of cell phone and booster apparatus (network of mobile).

It was noticed the mobile phone Nokia (Table 3), that the rate of hemoglobin was $15.12 \pm 0.31 \mathrm{~g} / \mathrm{dL}$ after exposure for 15 minutes, then the rate was decline to level of $14.38 \pm 0.51 \mathrm{~g} / \mathrm{dL}$ after 30 minute exposure time But the rate of hemoglobin value has more decline rate to $13.4 \pm 0.75 \mathrm{~g} / \mathrm{dL}$ and $11.3 \pm 1.48 \mathrm{~g} / \mathrm{dL}$ after exposure time of 45 and 60 minutes respectively. From the above results it is noticed that there is a decrease in the rate of hemoglobin after prolonged time periods when exposed to mobile phones compared with the average rate in the control group, which has $15.54 \pm 0.38 \mathrm{~g} / \mathrm{dL}$, and this was confirmed with the results of statistical analysis recorded in Table 4, which was detected the correlation coefficient (r) between measurements of blood and time in Short-term experiment, where it notes that there are inverse association between the rate of hemoglobin and the time periods after exposure to both types of mobile phone, i.e. that the rate of hemoglobin was decline with increasing periods of time, reaching a correlation coeffi-

Table 1. Hematological parameters of the exposed mice to the Al-Catel cell phone at time intervals 15, 30, 45 and 60 minutes daily from 6th to 8th week age.

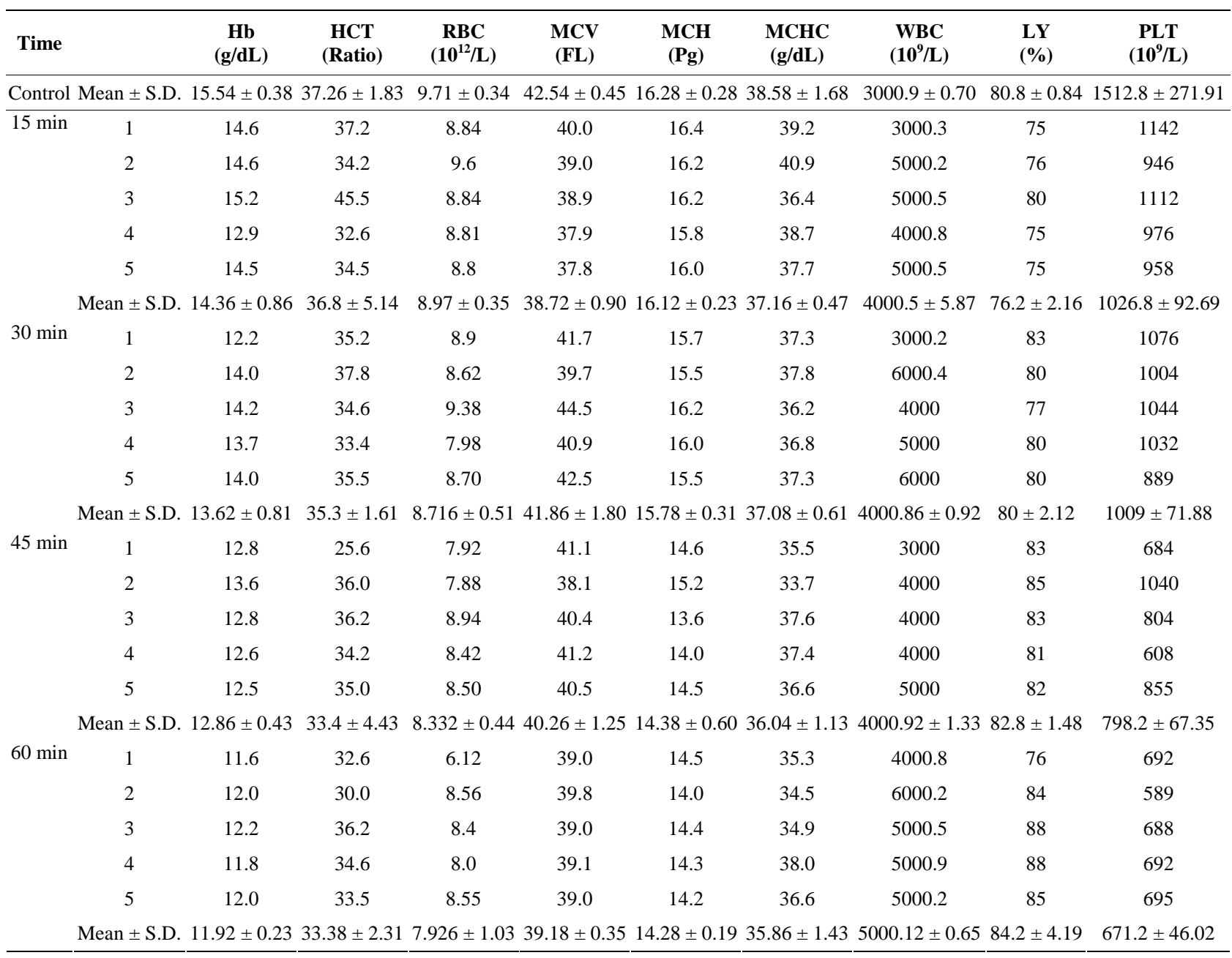


Table 2. Hematological parameters of the exposed mice for three months to two different types of cell phone and Booster apparatus (network of mobile).

\begin{tabular}{|c|c|c|c|c|c|c|c|c|c|c|}
\hline & & $\begin{array}{c}\mathbf{H b} \\
(\mathbf{g} / \mathbf{d L})\end{array}$ & $\begin{array}{c}\text { HCT } \\
\text { (Ratio) }\end{array}$ & $\begin{array}{c}\text { RBC } \\
\left(10^{12} / L\right)\end{array}$ & $\begin{array}{c}\text { MCV } \\
\text { (FL) }\end{array}$ & $\begin{array}{c}\text { MCH } \\
\text { (Pg) }\end{array}$ & $\begin{array}{c}\text { MCHC } \\
(\mathrm{g} / \mathrm{dL})\end{array}$ & $\begin{array}{l}\text { WBC } \\
\left(10^{9} / L\right)\end{array}$ & $\begin{array}{l}\text { LY } \\
(\%)\end{array}$ & $\begin{array}{c}\text { PLT } \\
\left(10^{9} / \mathrm{L}\right)\end{array}$ \\
\hline \multirow[t]{5}{*}{ Control } & 1 & 18.5 & 48.9 & 9.42 & 50.9 & 14.3 & 30.8 & 3000.2 & 76.4 & 585 \\
\hline & 2 & 16.8 & 48.6 & 9.23 & 51.4 & 19.2 & 38.1 & 3000.1 & 79.2 & 579 \\
\hline & 3 & 17 & 50 & 8.87 & 51.7 & 19.1 & 38.7 & 4000.2 & 72.1 & 680 \\
\hline & 4 & 16.8 & 49.6 & 9.96 & 50.0 & 18.6 & 38.8 & 5000.5 & 80.6 & 570 \\
\hline & 5 & 15.2 & 49.9 & 9.42 & 50.9 & 18 & 41 & 5000 & 75.4 & 582 \\
\hline
\end{tabular}

\begin{tabular}{ccccccccccc}
\multicolumn{2}{c}{ Mean \pm S.D. $16.86 \pm 0.65$} & $49.4 \pm 2.43$ & $9.38 \pm 0.39$ & $50.98 \pm 0.65$ & $17.84 \pm 2.03$ & $37.48 \pm 3.89$ & $4000.6 \pm 0.97$ & $76.74 \pm 3.33599 .2 \pm 45.52$ \\
AlCatel & 1 & 15.7 & 47.1 & 9.75 & 50 & 16.6 & 32.6 & 6000.6 & 83.8 & 615 \\
& 2 & 15.5 & 46.0 & 8.16 & 49.9 & 16.8 & 37.9 & 8000.1 & 81.3 & 525 \\
& 3 & 15.1 & 43.6 & 8.89 & 49.2 & 17.0 & 37.4 & 6000.7 & 69.0 & 570 \\
& 4 & 16.9 & 52.2 & 8.83 & 52.4 & 16.9 & 37.3 & 4000.7 & 77.0 & 671 \\
& 5 & 19.6 & 47.9 & 9.5 & 51.15 & 16.8 & 35.5 & 6000.4 & 76.4 & 592.5
\end{tabular}

\begin{tabular}{cccccccccccc}
\multicolumn{2}{c}{ Nokia } & Mean \pm S.D. $16.56 \pm 1.83$ & $47.36 \pm 3.15$ & $9.026 \pm 0.62$ & $50.53 \pm 1.26$ & $16.82 \pm 0.15$ & $36.14 \pm 2.18$ & $6000.5 \pm 1.21$ & $77.5 \pm 5.65$ & $594.7 \pm 54.09$ \\
& 1 & 14.5 & 45.7 & 8.97 & 46.5 & 16.1 & 33.3 & 5000.5 & 86.5 & 410 \\
& 2 & 13.9 & 41.9 & 8.15 & 50.5 & 17.1 & 33.7 & 8000.7 & 86.8 & 462 \\
& 3 & 14.5 & 45.0 & 8.7 & 49.5 & 16.6 & 34.6 & 8000.3 & 79.2 & 351 \\
& 4 & 15.0 & 44.6 & 8.92 & 48.0 & 16.8 & 32.3 & 7000 & 75.7 & 461 \\
& 5 & 14.45 & 43.8 & 8.43 & 43.8 & 16.6 & 33.45 & 7000.1 & 81.25 & 435
\end{tabular}

Mean \pm S.D. $14.47 \pm 0.39 \quad 44.2 \pm 1.46 \quad 8.634 \pm 0.34 \quad 47.66 \pm 2.63 \quad 16.64 \pm 0.36 \quad 33.47 \pm 0.83 \quad 7000.72 \pm 1.93 \quad 81.89 \pm 4.77423 .8 \pm 45.98$

Table 3. Hematological parameters of the exposed mice to the Nokia cell phone at time intervals $15,30,45$ and 60 minutes daily from 6th to 8th week age.

\begin{tabular}{|c|c|c|c|c|c|c|c|c|c|c|}
\hline Time & & $\underset{(\mathbf{g} / \mathbf{d L})}{\mathbf{H b}}$ & $\begin{array}{c}\text { HCT } \\
\text { (Ratio) }\end{array}$ & $\begin{array}{c}\text { RBC } \\
\left(10^{12} / L\right)\end{array}$ & $\begin{array}{c}\text { MCV } \\
\text { (FL) }\end{array}$ & $\begin{array}{c}\text { MCH } \\
\text { (Pg) }\end{array}$ & $\begin{array}{c}\text { MCHC } \\
\text { (g/dL) }\end{array}$ & $\begin{array}{c}\text { WBC } \\
\left(10^{9} / L\right)\end{array}$ & $\begin{array}{l}\text { LY } \\
(\%)\end{array}$ & $\begin{array}{c}\text { PLT } \\
\left(10^{\prime} / L\right)\end{array}$ \\
\hline Control & Mean \pm S.D. & $15.54 \pm 0.38$ & $37.26 \pm 1.83$ & $9.71 \pm 0.34$ & $42.54 \pm 0.45$ & $16.28 \pm 0.28$ & $38.58 \pm 1.68$ & $3000.9 \pm 0.70$ & $80.8 \pm 0.84$ & $1512.8 \pm 71.91$ \\
\hline \multirow[t]{5}{*}{$15 \min$} & 1 & 15.1 & 39.0 & 9.88 & 43.0 & 15.6 & 37.0 & 4000.3 & 81.0 & 1060 \\
\hline & 2 & 15.3 & 41.6 & 8.66 & 42.6 & 16.1 & 37.8 & 4000.3 & 71.0 & 1101 \\
\hline & 3 & 14.6 & 36.8 & 9.06 & 41.7 & 16.1 & 40.0 & 5000.8 & 66.0 & 1090 \\
\hline & 4 & 15.4 & 37.6 & 9.72 & 43.7 & 16.2 & 37.2 & 6000.6 & 78.0 & 1094 \\
\hline & 5 & 15.2 & 38.8 & 9.01 & 42.2 & 16.2 & 38.2 & 6000.5 & 75.0 & 1064 \\
\hline
\end{tabular}

Mean \pm S.D. $15.12 \pm 0.31 \quad 38.76 \pm 1.82 \quad 9.26 \pm 0.51 \quad 42.6 \pm 0.51 \quad 16.04 \pm 0.25 \quad 38.04 \pm 1.19 \quad 5000.54 \pm 1.90 \quad 74.2 \pm 5.89 \quad 1081.6 \pm 50.72$

$\begin{array}{rllllllllll}30 \mathrm{~min} & 1 & 15.2 & 38.6 & 9.1 & 38.8 & 15 & 36.4 & 4000 & 70.0 & 996 \\ & 2 & 14.1 & 34.4 & 9.58 & 39.4 & 14.1 & 37.0 & 6000 & 77.0 & 896 \\ & 3 & 14.2 & 35.4 & 8.72 & 40.2 & 14.7 & 38.0 & 6000.7 & 81.0 & 910 \\ & 4 & 13.9 & 38.0 & 8.88 & 40.4 & 14.2 & 38.3 & 4000.8 & 76.0 & 998 \\ & 5 & 14.5 & 36.6 & 9.0 & 40.2 & 14.4 & 38.0 & 5000.2 & 80.0 & 989\end{array}$

Mean \pm S.D. $14.38 \pm 0.51 \quad 36.6 \pm 1.75 \quad 9.056 \pm 0.32 \quad 39.62 \pm 1.52 \quad 14.46 \pm 0.26 \quad 37.54 \pm 0.80 \quad 5000.98 \pm 1.10 \quad 76.8 \pm 4.32 \quad 957.8 \pm 50.38$

$\begin{array}{cccccccccccc}45 \min & 1 & 14.4 & 20.7 & 7.28 & 36.3 & 14.6 & 36.2 & 7000 & 84.0 & 848 \\ & 2 & 12.8 & 37.6 & 7.22 & 40.1 & 14.8 & 36.0 & 6000.8 & 86.0 & 874 \\ & 3 & 12.8 & 34.0 & 9.04 & 40.2 & 14.1 & 37.0 & 7000 & 85.0 & 874 \\ & 4 & 14.0 & 36.0 & 8.36 & 37 & 14.4 & 37.7 & 4000.6 & 78.0 & 1026 \\ & 5 & 13.0 & 36.5 & 8.45 & 40.5 & 14.4 & 36.5 & 6000.5 & 86.0 & 877\end{array}$

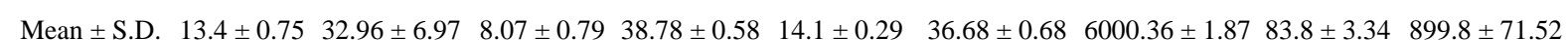

$\begin{array}{lllllllllll}60 \min & 1 & 9.6 & 27.2 & 4.82 & 42.8 & 13.2 & 35.6 & 5900.9 & 88.0 & 508 \\ & 2 & 10.0 & 29.0 & 8.84 & 41.7 & 13.9 & 40.0 & 7000.6 & 86.0 & 450 \\ & 3 & 13.0 & 37.2 & 8.14 & 43 & 14.4 & 33.7 & 7000.6 & 88.0 & 622 \\ & 4 & 12.4 & 32.6 & 8.26 & 42.6 & 14.8 & 34.1 & 6000.9 & 84.0 & 436 \\ & 5 & 11.5 & 35.5 & 8.15 & 43.1 & 14.2 & 33.5 & 6000.6 & 86.0 & 450\end{array}$

Mean \pm S.D. $\quad 11.3 \pm 1.48 \quad 32.3 \pm 4.22 \quad 7.642 \pm 1.6042 .64 \pm 0.76 \quad 14.1 \pm 0.60 \quad 35.38 \pm 2.71 \quad 6380 \pm 178.88 \quad 86.4 \pm 1.67 \quad 493.2 \pm 77.16$ 
cient $\mathrm{r}=-0.998$ for Alcatel. The high significant correlation $\mathrm{P}=0.002$, while the correlation coefficient when exposed to Nokia was $r=-0.969$. The significance was at probability of $\mathrm{P}=0.31$.

The results of the long-term experiment were observed in Table 4. There was a decrease in the average rate of hemoglobin when exposed to mobile phone Alcatel reaching $16.56 \pm 1.83 \mathrm{~g} / \mathrm{dL}$, the rate of hemoglobin exposure for mobile phone Nokia was $14.47 \pm 0.39 \mathrm{~g} / \mathrm{dL}$ and that compared to the control group of long-term experiments their rate of hemoglobin was $16.86 \pm 0.65$ was $\mathrm{g} / \mathrm{dL}$.

Statistical analysis of the comparison between the rate of hemoglobin in the control group and the rate of hemoglobin after exposure to mobile phones was illustrated in (Table 5). The significant difference was non-moral reaching p values of 0.085 to Alcatel while 0.28 for Nokia, and when comparing between the two types of mobile phone, the differences between them were significant reaching p values of 0.037 .

It was noticed that the results of the average rate of hematocrit in the control group in the short-term experiment (Tables 1 and 3), the value of $37.26 \% \pm 1.83 \%$, while there was a decrease in the value of this index when exposed to mobile phone Alcatel and that for 15 minutes reach $36.8 \% \pm 5.14 \%$ and reached $35.3 \% \pm$ $1.61 \%$ when exposed for 30 minutes and then continued to decline up to $33.4 \% \pm 4.43 \%$ and $33.38 \% \pm 2.31 \%$ at the two time periods 45 and 60 minutes respectively. There was observed proportional reduction in the hematocrit when exposed to 15 minutes for mobile phone Nokia (38.76\% $\pm 1.82 \%)$, then the reduction continued to reach $32.3 \% \pm 4.22 \%$ when exposed for 60 minutes. The study shows statistical analysis of correlation coefficient Table 4 that after exposure to mobile phone Alcatel was inversely $r=-0.949$. This was the correlation a meaning non-significant $\mathrm{r}<0.950$. Also it inversely with significance value $\mathrm{P}=0.028$ when exposed to Phone Nokia mobile phone, where the correlation coefficient was reached -0.972 .

Results of the hematocrit in long-term experiments

Table 4. The correlation coefficient for the hematological parameters of the exposed mice to two different types of cell phone at time intervals 15, 30, 45 and 60 minutes daily from 6th to 8th week age.

\begin{tabular}{ccccc}
\hline & \multicolumn{2}{c}{ Al-Catel } & & Nokia \\
\cline { 2 - 5 } & $\mathbf{r}$ & $\mathbf{P}$ & $\mathbf{r}$ & $\mathbf{P}$ \\
\hline Hb (g/dL) & -0.998 & 0.002 & -0.969 & 0.031 \\
HCT (Ratio) & -0.949 & $0.051^{*}$ & -0.972 & 0.028 \\
RBC (10 $\left.\mathbf{1 0}^{\mathbf{1 2}} \mathbf{L}\right)$ & -0.995 & 0.005 & -0.971 & 0.029 \\
MCV (FL) & -0.990 & 0.010 & -0.939 & $0.061^{*}$ \\
MCH (Pg) & -0.0944 & $0.056^{*}$ & -0.897 & $0.103^{*}$ \\
MCHC (g/dL) & -0.938 & $0.062^{*}$ & -0.980 & 0.020 \\
WBC (10 $/ \mathbf{L})$ & 0.774 & $0.226^{*}$ & 0.923 & $0.077^{*}$ \\
LY (\%) & 0.980 & 0.020 & 0.980 & 0.020 \\
PLT (10 $\mathbf{9} / \mathbf{L})$ & -0.0961 & 0.039 & -0.960 & 0.040
\end{tabular}

Table 5. Statistical analysis for the hematological parameters of the exposed mice for three months to two different types of cell phone and Booster apparatus (net work of mobile).

\begin{tabular}{|c|c|c|c|c|c|c|c|c|c|c|c|c|c|c|c|c|c|c|}
\hline \multirow{2}{*}{$\begin{array}{c}\text { The } \\
\text { comparison }\end{array}$} & \multicolumn{2}{|c|}{$\begin{array}{c}\text { Hb } \\
(\mathrm{g} / \mathrm{dL})\end{array}$} & \multicolumn{2}{|c|}{$\begin{array}{c}\text { HCT } \\
\text { (Ratio) }\end{array}$} & \multicolumn{2}{|c|}{$\begin{array}{c}\text { RBC } \\
\left(10^{12} / \mathrm{L}\right)\end{array}$} & \multicolumn{2}{|c|}{$\begin{array}{l}\text { MCV } \\
\text { (FL) }\end{array}$} & \multicolumn{2}{|c|}{$\underset{(\mathrm{Pg})}{\mathrm{MCH}}$} & \multicolumn{2}{|c|}{$\begin{array}{c}\text { MCHC } \\
\text { (g/dL) }\end{array}$} & \multicolumn{2}{|c|}{$\begin{array}{c}\text { WBC } \\
\left(10^{9} / \mathrm{L}\right)\end{array}$} & \multicolumn{2}{|c|}{$\begin{array}{l}\text { LY } \\
(\%)\end{array}$} & \multicolumn{2}{|c|}{$\begin{array}{c}\text { PLT } \\
\left(10^{9} / \mathrm{L}\right)\end{array}$} \\
\hline & $\mathbf{t}$ & $\mathbf{P}$ & $\mathbf{t}$ & $\mathbf{P}$ & $\mathbf{t}$ & $\mathbf{P}$ & $\mathbf{t}$ & $\mathbf{P}$ & $\mathbf{t}$ & $\mathbf{P}$ & $\mathbf{t}$ & $\mathbf{P}$ & $\mathbf{t}$ & $\mathbf{P}$ & $\mathbf{t}$ & $\mathbf{P}$ & $\mathbf{t}$ & $\mathbf{P}$ \\
\hline $\begin{array}{c}\text { control and } \\
\text { Al-Catel }\end{array}$ & 1.96 & $0.085^{*}$ & 4.47 & 0.0021 & 1.07 & $0.31^{*}$ & 2.20 & $0.059^{*}$ & 0.14 & $0.89^{*}$ & 0.67 & $0.52^{*}$ & 2.14 & $0.065^{*}$ & 2.45 & 0.040 & 0.14 & $0.89^{*}$ \\
\hline $\begin{array}{l}\text { control and } \\
\text { Nokia }\end{array}$ & 1.16 & $0.28^{*}$ & 3.78 & 0.0054 & 3.19 & 0.013 & 5.11 & 0.0009 & 6.06 & 0.0003 & 2.58 & 0.033 & 3.31 & 0.011 & 1.83 & $0.10^{*}$ & 6.06 & 0.0003 \\
\hline $\begin{array}{l}\text { Al-Catel and } \\
\text { Nokia }\end{array}$ & 2.5 & 0.037 & 2.03 & $0.076^{*}$ & 1.23 & $0.25^{*}$ & 1.43 & $0.19^{*}$ & 1.02 & $0.34^{*}$ & 3.17 & 0.013 & 1.36 & $0.21^{*}$ & 0.26 & $0.80^{*}$ & 5.38 & 0.0007 \\
\hline
\end{tabular}


(after three months) were tabulated in Table 2, it was noted that the percentage of hematocrit in the blood of the control group reached $49.4 \% \pm 2.43 \%$. There was a decrease in the percentage of hematocrit, scoring value of $47.36 \% \pm 3.15 \%$ and $44.2 \% \pm 1.46 \%$ in mice exposed to Alcatel and Nokia mobile phone respectively. If compareing the devices used for the control group in Table 5 (the statistical analysis), it noticed that there was highly significant difference between the percentage of hematocrit in the control group and its counterparts when exposed to mobile phones, which reported p values of 0.0021 when comparing the control group with Alcatel, while 0.0054 when compared between the control group with Nokia, and also observed the statistical analysis of the Table 5, the significant differences between the two types of mobile phone was non-significant at $\mathrm{P}>0.05$. In the shortterm experiments, the average number of red blood cells in the group that was exposed to mobile phone Alcatel for 15 minutes had reached the $8.97 \pm 0.35(1012 / \mathrm{L})$ and then taking the fall-out to score at 30 minutes value of $8.71 \pm 0.51(1012 / \mathrm{L})$, and after exposure for 45 minutes taking the value of $8.33 \pm 0.44(1012 / \mathrm{L})$, while the value to less exposure for 60 minutes (Tables 1 and 3), as was $7.92 \pm 1.03(1012 / \mathrm{L})$.

There was decline also detected in the case of exposure to Nokia mobile phone where the average number of red blood cells at 15 minutes the value 9.26 \pm 0.51 $(1012 / \mathrm{L})$ and then declining to record at 30-minute value of $9.056 \pm 0.32(1012 / \mathrm{L})$ and then continued to decline, reaching $7.64 \pm 1.60(1012 / \mathrm{L})$ at the time 60 minutes. Comparing the results of Alcatel and Nokia to the control group, it is noted that the average red blood cell count has fallen under the influence of exposure to the two mobile phone compared to the control group, which has a number of red blood cells $9.71 \pm 0.34(1012 / \mathrm{L})$, the highest readings recorded in the Alcatel and Nokia.

In Table 4, there was inverse association between the number of red blood cells and the time periods when exposed to two types of mobile phone, which means that red blood cells under increasing periods of time, as it recorded the correlation coefficient when exposed to mobile phone Alcatel value $r=-0.995$, and highly significant $\mathrm{P}=0.005$, while the correlation coefficient on exposure to Nokia mobile phone value $r=-0.971$, and highly significant $r<0.950$. From Table 2 (long-term experiment), it was observed that when exposed to Alcatel mobile phone for half hours a day for three consecutive months the number of red blood cells was 9.026 $\pm 0.62(1012 / \mathrm{L})$, then decline down slightly to the control group, which has the number of red blood cells by the $9.38 \pm 0.39(1012 / \mathrm{L})$, and Nokia mobile phone, the average number of red blood cells $8.634 \pm 0.34(1012 / \mathrm{L})$. Where the results of statistical analysis (Table 5), it was noted that when comparing the number of red blood cells in the control group with their counterparts after exposure to Alcatel mobile phone, the significant differences between them were non-significant $\mathrm{P}=0.31$ while the significant difference comparing the average reading group control and Nokia mobile phone was $P=0.013$. And a comparison between two types of mobile phone, it was observed that the differences in the average number of red blood cells between them was not significant $\mathrm{P}=$ 0.25 .

Table 1 represented that when exposed to mobile phone Alcatel for 15, 30, 45 and 60 minutes MCV value was $38.72 \pm 0.90,41.86 \pm 1.80,40.26 \pm 1.25$ and $39.18 \pm$ 0.35 FL respectively. While MCV value in case of mobile phone Nokia (Table 3) was $42.6 \pm 0.51 \mathrm{~F}$ when exposed for 15 minutes and then decreased gradually when exposed to two time periods 30.45 minutes, (39.62 \pm 1.52 and $38.78 \pm 0.58 \mathrm{FL}$ ) respectively, then the MCV value when exposed for 60 minutes, reached $42.64 \pm$ 0.76 FL.

It was noted that the average of MVC was decreased significantly when exposed to mobile phones compared with the control group reached the average value of 42.54 \pm 0.45 FL (Table 4). The statistical analysis, revealed that it is noted that there are inverse association between the size of red blood cell and exposure times; an increase of exposure times less than the average size of the pellet and that when exposed to two types of mobile phone was recorded correlation coefficient size of the red cells when exposed to Alcatel mobile phone was $r=-0.990$, and it was significant, while the correlation is significant at $\mathrm{P}=$ 0.061 when the exposure of Nokia reaching correlation coefficient $\mathrm{r}=-0.939$.

In the long term experiments a recorded reading in Table 4, the average MVC value when exposed to Alcatel mobile phone was $50.53 \pm 1.26 \mathrm{FL}$, also reached in the Nokia $2.63 \pm 47.66 \mathrm{FL}$. It has been observed that there decrease in the average MVC value when exposed to mobile phones compared to the control group, the average MVC value was $50.98 \pm 0.65 \mathrm{FL}$. When comparing the MVC value in the control group with an average MVC value when exposed to two phone adapter, seen from the table of statistical analysis no. (5), that there were differences not significant between the control group, Alcatel ( $\mathrm{P}=0.059$ ), while the correlation differrence of MVC value was highly significant $(P=0.0009)$ when exposure to the Nokia compared to controls. Comparing the middle-size red blood corpuscle with two types of mobile phone Alcatel, Nokia, the correlation differences between them were not significant, reaching $\mathrm{P}=0.19, \mathrm{P}$ $=0.0002$.

It was observed from the Table 1, that when exposed to Alcatel mobile phone for 15 minutes, the average weight of hemoglobin in red blood cell (MCH) $16.12 \pm$ 0.23 with increasing duration of exposure the average 
weight of hemoglobin ball in the gradual decrease reaching $15.78 \pm 0.31$ and $14.38 \pm 0.60 \mathrm{Pg}$ when exposure time 30.45 minutes respectively, and scored lower value $14.28 \pm 0.19 \mathrm{Pg}$ when exposure for 60 minutes. While Nokia mobile phone (Table 3) showed that the average weight of hemoglobin value was16.04 $\pm 0.25 \mathrm{Pg}$ when exposed for 15 minutes, then taken for the gradual reduction of the score values of $14.46 \pm 0.26,14.1 \pm 0.29$ and $14.1 \pm 0.60 \mathrm{Pg}$ after exposure time 30, 45 and 60 minutes respectively. Comparing the two types of mobile phone together notes that Nokia has recorded the highest decline of Alcatel's mobile phone if compared with the control group where the average MCH value was $16.28 \pm$ 0.28 Pg. Given the scale statistical analysis Table 4, it is noted that the correlation between the average weight of hemoglobin in red blood cell and the time exposure to both types of mobile phone was reverse and significant, where was the correlation coefficient $\mathrm{r}=-0.944$ for Alcatel and $\mathrm{r}=-0.897$ for Nokia, as reported $\mathrm{P}$ values are 0.056, 0.103 for Alcatel and Nokia respectively.

In the long-term experiment, it is noted from Table 2 that the average weight of hemoglobin in red blood cell has reached in the control group $17.84 \pm 2.03$ Pg, while there was a significant decrease in value when exposed to mobile phones, where the exposure to Alcatel mobile phone was $16.82 \pm 0.15 \mathrm{Pg}$, recorded while when exposed to Nokia mobile phone, the value was $16.64 \pm 0.36$ Pg. The statistical analysis recorded in Table 5, it was observed if compared the average weight of hemoglobin with the control group when exposed to two mobile phones, and the correlation differences were significant reaching $\mathrm{P}$ values 0.30 . When comparing the control group with Alcatel, it reached 0.23 when comparing between the control group and Nokia.

Comparing the middle-weight hemoglobin red blood cell when exposed to two types of mobile phone, the correlation differences between them were significant with $\mathrm{P}=0.34$.

In a Table 1 could observed that when exposed to Alcatel mobile phone for 15 and 30 minutes the MCHC values were $37.16 \pm 0.47 \mathrm{~g} / \mathrm{dL}$ and $37.08 \pm 0.61 \mathrm{~g} / \mathrm{dL}$ respectively. With the increased exposure time to $60 \mathrm{~min}$ utes there was a decline in average concentration to reach its lowest value $35.86 \pm 1.43 \mathrm{~g} / \mathrm{dL}$. The Nokia mobile phone Table 3, observed the MCHC value of $38.04 \pm$ $1.19 \mathrm{~g} / \mathrm{dL}$ when exposed for 15 minutes, then by increasing exposure time it was noted a significant decrease in the MCHC to reach its lowest value at the highest exposure time 60 minutes, which recorded the $35.38 \pm 2.71$ $\mathrm{g} / \mathrm{dL}$. The exposure of mobile phone observed a decrease in the MCHC if compared with control group. The study confirmed statistically in Table 2 the existence of inverse association between the average MCHC and the exposure time, it has reached the correlation coefficient between the MCHC and periods of exposure to Alcatel -0.938 and was a sign of non-significant $r<0.950$, while in case of Nokia have highly significant in correlation coefficient value -0.980 , where $P$ value was 0.020 .

In the long-term experiment in Table 2, it was noted that the MCHC in the control group was $37.48 \pm 3.89$ $\mathrm{g} / \mathrm{dL}$, then taken to decrease when exposure to mobile phones where the total exposure to mobile phone Alcatel $36.14 \pm 2.18 \mathrm{~g} / \mathrm{dL}$. Nokia and recorded the value $33.47 \pm$ $0.83 \mathrm{~g} / \mathrm{dL}$. Table 5 noted that, comparing the MCHC in the control group with the MCHC after exposure to mobile phones, the correlation difference was significant when compared with the control group. The Alcatel was $\mathrm{P}=0.52$, while the correlation differences was significant when comparing the control group, in Nokia was $\mathrm{P}$ $=0.033$. When comparing the two types of mobile phone to each other, the correlation differences in mean MCHC between the two was significant moral value is recorded as $\mathrm{P}=0.013$.

Tables 1 and 3 noted that the average number of white blood cells in the control group in short-term experiment was $3000.9 \pm 0.70$ (109/L), while when exposed to Alcatel mobile phone for 15 minutes the average number of white blood cells was $4000.5 \pm 5.87(109 / \mathrm{L})$, and then rise after exposure for 30 minutes (4000.8 \pm 0.92$), 45$ minutes ( $4000.92 \pm 1.31$ ) reach the highest value 5000.12 $\pm 0.65(109 / \mathrm{L})$ after exposure for 60 minutes. The exposure to Nokia mobile phone (Table 3) revealed that there was an increase in the average number of white blood cells with increasing of exposure time, as the average number of cells when exposed for 15 minutes value of $5000.54 \pm 1.90(109 / \mathrm{L})$ of up to $6380 \pm 1.78(109 / \mathrm{L})$ at exposure for 60 minutes, which is the highest value was recorded in short-term experiment. It has been observed from the statistical values recorded in Table 4, that there was a direct strong link relationship between the number of white blood cells and duration of exposure to mobile phone quality, which means that there is an increase in the number of white blood cells when increasing the time exposure when exposed to Alcatel mobile phone and also Nokia mobile phone, where the correlation coefficient reached in the case of exposure to Alcatel $r=0.774$ and to Nokia was 0.923 , with high significant $r<0.950$. The long-term experiment (after three months of exposure to the two mobile phone) was observed in Table 2 that the average total number of white blood cells in the control group was $4000.6 \pm 0.9790(109 / \mathrm{L})$, and when exposed to two phone mobile, there was a marked increase in the average number of white cells, reaching a value when exposed to mobile phone Alcatel $6000.5 \pm 1.21$ and Nokia $7000.72 \pm 1.93(109 / \mathrm{L})$. The study proved the statistical analysis in Table 5, which showed that comparing the average number of white cells in the control group the average number after exposure to two mobile phone, 
there are correlation differences was not significant between the control group, Alcatel $\mathrm{P}=0.065$, while the correlation difference was significant between the control group, Nokia and reached $\mathrm{P}=0.011$. When compared statistically between the two mobile phone, the correlation differences were between the highly significance in Alcatel and Nokia $P=0.21$. The increase in the number of white blood cells in the short and long term experiments showed that there is resistance of the body against the outgoing radiation from the various devices.

Results of short-term experiment (Table 1) observed that the percentage of lymphocytes in the control group reached $80.8 \% \pm 0.84 \%$. After exposures to Alcatel mobile phone the percentage of lymphocytes were raised with increasing periods of time and reached the highest rate it at 60 minutes $(84.2 \% \pm 4.19 \%)$. But when exposed to Nokia mobile phone the highest rate it at 60 minutes was $(86.4 \% \pm 1.67 \%)$. Notes from previous readings that when exposure to both types of mobile phone, there was an increase in the percentage of lymphocytes when increased periods of exposure and this confirmed by statistical analysis (Table 4), that there is a direct relationship between the percentage of lymphocytes and exposure time and in the case of exposure to Alcatel mobile phone was $r=0.980$, and also in the case of exposure to Nokia $r$ $=0.980$, and the correlation in both cases showed significant value 0.020 . Results of the long term experiment (Table 2), it was observed an increase in the percentage of lymphocytes if compared with the control group. The average percentage of lymphocytes was $76.74 \% \pm 3.33 \%$ either when exposed to Alcatel mobile phone which has reached the proportion of lymphocytes $77.55 \% \pm 5.65 \%$ while Nokia was $81.89 \% \pm 4.77 \%$. The statistical analysis (Table 5), noted that when compared to the average percentage of lymphocytes in the control group with Alcatel mobile phone, the differences between them were significant 0.40 while the differences were not significant in the Nokia mobile phone $\mathrm{P}=0.10$. Comparing the percentage of lymphocytes when exposed to Alcatel, Nokia mobile phones were non-significant $\mathrm{P}$ value $<0.88$.

Results of Table 1 revealed that, the average platelet count was $1026.8 \pm 92.69(109 / \mathrm{L})$ when exposed to Alcatel mobile phone for 15 minutes then decline signifycantly with increasing exposure time periods (60 minutes was $671.2 \pm 46.02(109 / \mathrm{L})$. Table 3 (Nokia mobile phone) observed that when exposed to a 15-minute average platelet count $1081.6 \pm 50.72(109 / \mathrm{L})$, and then declined to reach the lowest value when exposed for 60 minutes $(493.2 \pm 77.16)$. It was noticed that the average number of platelets in the control group in the short-term experiment record value of $1512.8 \pm 271.91$ (109/L). The study showed statistically recorded in Table 4, that there was inverse association between the average number of platelets and time of exposure to mobile phones, an increase of periods of exposure to mobile phones, the number of platelets was lowered. The correlation coefficient when exposed to Alcatel and Nokia mobile phone was of the values of $0.961,0.960 \mathrm{r}=$ respectively, It has a moral significance $\mathrm{P}=0.039$ when exposed to Alcatel, and also when exposed to Nokia $P=0.040$. Results of the long-term and experiment (Table 2) indicates a decline in the average number of platelets compared to control group at which the average $599.2 \pm 45.52$ (109/L), while when exposed to mobile phone Alcatel record the average number of platelets value $594.7 \pm 54.09(109 / \mathrm{L})$, and when exposed to mobile phone Nokia was $423.8 \pm 45.98$ $(109 / \mathrm{L})$. Comparing the number of platelets in the control group with those after exposure to mobile phones as shown in Table 5, it was noted that there was no signifycant difference between the control group and Alcatel (P $=0.89)$, Nokia $(P=0.003)$. The comparison between the two mobile phone, the differences between them were of highly significant $P=0.0007$.

Results of short-term experiment in this part of the research on blood samples from mice two weeks after exposing them to radiation Alcatel and Nokia mobile phone separately, at different periods of time 15, 30, 45 and minutes, and then stained with Giemsa stain. Figure 1 representative to smear the blood of the control group the age of 8 weeks (i.e., the end of the short-term experiment) to red blood cells retain the form in its natural to some extent, a format disc and has a membrane of a cell and do not contain nuclei, therefore, not known as red blood cells but called the red blood cells, and cells appeared regular sizes and forms as pellets containing a compound of hemoglobin. When animals were exposed to Alcatel form mobile phone and the Nokia mobile phone shape for 15 minutes, did not notice a clear difference between the smears of blood under the influence of the two devices. Red blood cells were retained in their natural form to a large extent, close to the structure present in the control group also existed some cells stacked next to each other to form rouleaux, any cell-shaped compact, which appear in the (Figure 2) line intermittently, and attributed emergence of cells in this format to the ability of red blood cells to stick to one and collected after the other due to the increased viscosity of blood, when exposed to any stimuli or due to the onset of symptoms slightly. Increased duration of exposure to Alcatel and Nokia for 30 minutes as observed in (Figure 3), there

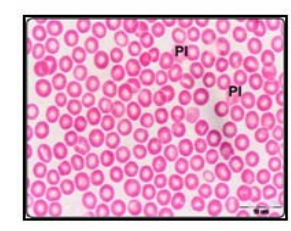

Figure 1. Blood smear of control group mice, showing normal appearance of erythrocytes and blood platelets (PI) can be seen. Giemsa stain. 

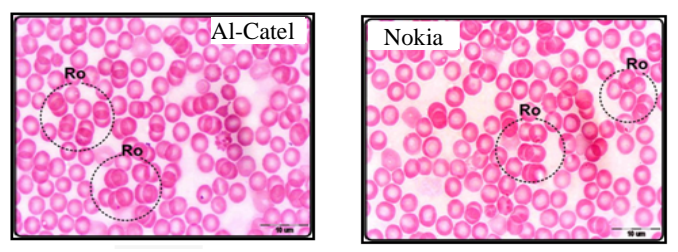

Figure 2. Blood smear of exposed mice to AI-Catel and Nokia cell phone for 15 minutes, showing Rouleaux erythrocytes (Ro). Giemsa stain.
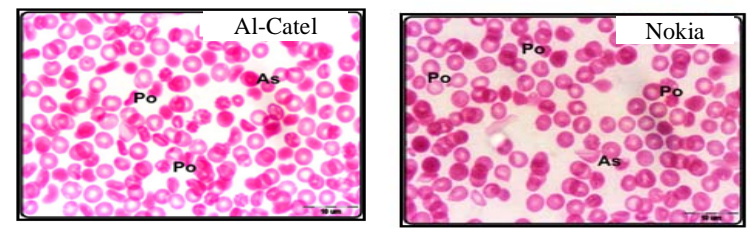

Figure 3. Blood smear of exposed mice to AI-Catel cell and Nokia phone for 30 minutes, showing Anisocytosis (As) and poikilocytosis of erythrocytes (Po), as well as pale corpuscles can be seen. Giemsa stain.

were some cells shows celled irregular, including round and oval or kidney, etc., Anisocytosis (As) and poikilocytosis of erythrocytes (Po), as well as pale corpuscles can be seen. Giemsa stain.

Figure 4 showed that the mobile phone Nokia has had a stronger effect on the blood, where a shortage in the intensity of coloring inside the red blood cells and appear pale due to lack of concentration of hemoglobin (Hypochromia, Hy), and this is confirmed as shown in Table 3.

It was noted that the exposed animals for longer period up to 60 minutes (Figure 5), which represents swab of the blood of mice that had been Alcatel appearance of varying red blood cells sizes (Anisocytosis). As noted in the (Figure 5) which representative of the smears of blood after exposure to mobile phone Nokia for $60 \mathrm{mi}-$ nutes. It was shown a large proportion of the red blood cells as spherocytes as well as the presence of large numbers of blood cells, which noted increase in pigmentation of the red blood cells as a result of the acquisition of hemoglobin with large amount of stain known as the polychromia.

In this part of the research animals were exposed to long periods (long-term experiment) of time and that of mobile phones on both the above-mentioned unit (Alcatel, Nokia) for an hour and a half a day, every day without interruption and continue the exposure of three consecutive months. Many of the pathological changes of red blood cells were observed after exposure to the Alcatel and Nokia devices (Figure 6). The red blood cells with seriated wall were observed with different number of humps and other showed cover surround red blood cells from the outside, this shows red blood cells serrated with the edge, the cells called burr cells or called Echinocytes erythrocytes.
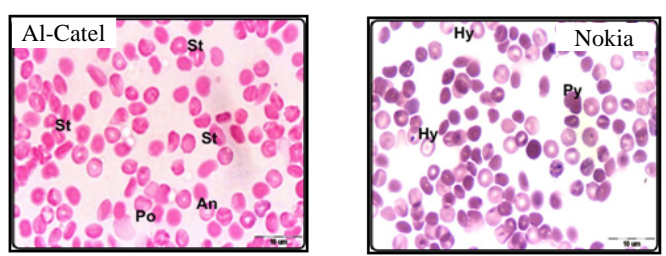

Figure 4. Blood smear of exposed mice to AI-Catel and Nokia cell phone for 45 minutes, showing Poikilocytosis (Po) Anisochromia (An) and Stom atocytosis (St) erythrocytes. Giemsa stain.
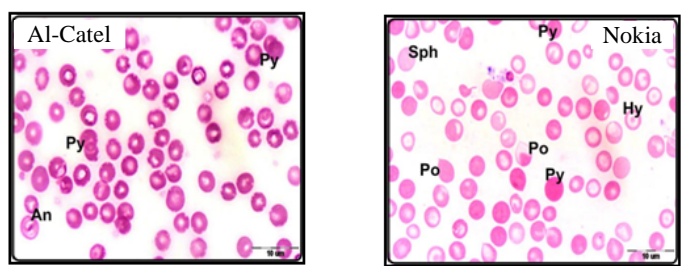

Figure 5. Blood smear of exposed mice to AI-Catel and Nokia cell phone for 60 minutes, showing Polychromic (Py) and Anisochromia (An) erythrocytes. Giemsa stain.
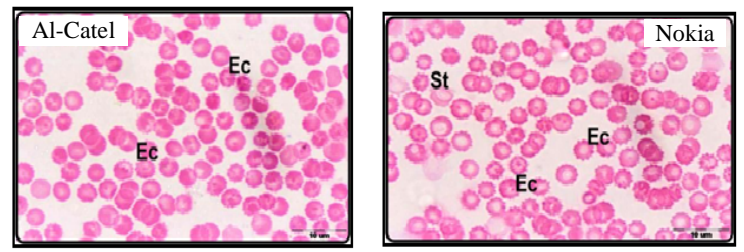

Figure 6. Blood smear of exposed mice to AI-Catel and Nokia cell phone after three months of exposure, showing large number of Echinocytic erythrocytes (Ec). Giemsa stain.

\section{Discussion}

Measurements of blood parameters are most important means by which to determine the health status of experimental animals [24]. Fatayer [22] noted that these measurements are diagnostic for certain diseases such as anemia, leukemia and detect the presence of the inflamemation. The decrease in numbers of red blood cells was showed in some diseases as anemia. The evidenced of the increase in the number of red blood cells indicated that the presence of disease which increases of production of red blood cells as Polycythaemia due to disorder in the bone marrow [22]. Mean Corpuscular Haemoglobin $(\mathrm{MCH})$ has medical importance in the diagnosis of some types of anemia, where indicates the decrease in the value of MCH on the disease of anemia caused by iron deficiency, and the unit of measurement used is Picogram (Pg) [25].

Indices of red blood cells RBC which is closely related to red blood cells which gives a clear picture of performance and efficiency of functional red blood cells, and also a copy of the rate of hemoglobin concentration, and describes the increase and decrease in the volume of red 
blood cells [26]. The most important of these indices: The average size of the red cells (mean cell volume, MCV), which helps in the diagnosis of some diseases, decreased in the size of the red cells showed in anemia of the Mediterranean known as the microcytic anemia, while The increase in the average size of the red cells lead to macrocytic anemia. Fatayer [22] reported that the mean corpuscular haemoglobin concentration (MCHC) index helps in the diagnosis of different types of anemia.

It was clear from the current study that there is a significant reduction in the measurements of the blood and the most important of hemoglobin $\mathrm{Hb}$, and hematocrit Hct, in addition to the number of indices of red blood cells are RBC, MCV, MCH, MCHC, was also noted that the decline in the average number of platelets, PLT when increasing periods of exposure in the short and long term experiments under the influence of the devices used in the search, and this decline is an indication of different types of anemia, as well as leukemia [19].

While it was observed a significant increase in the average number of white blood cells WBC as well as the proportion of lymphocytes Ly and this increase is accompanied with cases of anemia, as macrocytic anemia, it is also evidence of bleeding, which arise under the influence of exposure to radiation and increased temperature and resistance the body [27]. The increase in the percentage of lymphocytes associated with lymphatic leukemia, or inflammation of the lymph gland, which appear as a result of constant exposure to electromagnetic waves, especially the children, where Zelly [28] acting out to increase the possibility of children affected with leukemia as a result of exposure to these waves. These results agree with the Michelozzi et al. [12], who stated that of the housing near the relay networks led to leukemia, also Anderson \& Henderson [29], Maskarines, et al. [30] carried out various studies in Hawaii and Australia. Also Mckenzie, et al. [31] proved a relationship between exposure to electromagnetic waves issued from the mobile phone or from the vibrations of the strengthening of networks, electricity and blood cancer (leukemia). Another [32] about increased incidence of children who die from cancer of the blood, they found that the rate of death reached two to three times in places near highvoltage lines than children who die in areas not containing the high-voltage lines. On the other hand some studies have shown that there is no damage to the blood as a result of exposure to electromagnetic field [33]. Although there are risks as leukemia from using mobile phones, but Ikeda, et al. [34], stated that cannot really say that, as there has been no change in white blood cells to humans when exposed to waves of frequency $50 \mathrm{~Hz}$. Dennis, et al. [35] stated that cannot confirm or reach a final result of leukemia for residents near the mobile phone networks to strengthen due to the different envi- ronment and experience is difficult to estimate the proportion of exposure among individuals. This is consistent with Verkasalo, et al. [36] and Kleinerman, et al. [37] who found that there was no relationship between children's exposure to the electromagnetic field and cancer, especially leukemia. National Academy of Sciences in California, also mentioned that they did not find a clear threat to residents near the network relay or working in the electromagnetic field and it is not directly related to leukemia, but left the door open for further research, especially cancer of the blood of children [38].

Blood in vertebrates consists of a liquid plasma, exists in which red blood cells which takes the form of tablets round concave sides, and not the nuclei of each globule is surrounded by thin membrane is flexible and contains the haemoglobin and inorganic salts [39] and there are also white blood cells. White blood cells in the blood there is also a small structure located in the plasma of these structures and shatter easily when contact with any rough surface, especially at the exit of blood from the blood vessels and these structures are called platelets Blood Platelets. In the current research the blood smears at the end of periods of the experiment and after exposing the animals to radiation from the devices were investigated by filmed swabs of blood to study the changes that occur in many shapes and sizes of red blood cells and recording what happens from defects or changes in these pellets, and these changes are of particular importance where the scientists used to estimate the extent of stress on the animals from the environment in which they live.

Results of short-term experiment in this part of the research on blood samples from mice two weeks after exposing them to radiation Alcatel and Nokia mobile phone separately, at different periods of time 15, 30, 45 and minutes, and then stained with Giemsa stain. When animals were exposed to Alcatel form mobile phone and the Nokia mobile phone shape for 15 minutes, did not notice a clear difference between the smears of blood under the influence of the two devices [20]. Red blood cells were retained in their natural form to a large extent, close to the structure present in the control group also existed some cells stacked next to each other to form rouleaux, any cell-shaped compact, line intermittently, and attributed [40] emergence of cells in this format to the ability of red blood cells to stick to one and collected after the other due to the increased viscosity of blood, when exposed to any stimuli or due to the onset of symptoms slightly.

These results was observed by Dudek [20] who found that these forms or the difference in abnormal forms of red blood cells, the term erythrocytes Poikilocytosis, as shown in the smears variation in the sizes of red blood cells, called this phenomenon Anisocytosis.

It was clear from previous readings and recorded in 
Tables 1 and 2 decreased the average size of red blood cells in Alcatel to reach $41.86 \pm 1.80$ FL while the exposure of Nokia average size of red blood cells $39.62 \pm 1.52$ FL red blood cells here has the scientific name of Microcytic any (red blood cells small), compared with an average size of the red blood cells in the control group, which has $42.54 \pm 0.45 \mathrm{FL}$.

The presence of some cells were pale colour with an increased rate of color fading in the swabs from mice which were exposed to a Nokia has been attributed Dudek [20] appearance of color fading in the cytoplasm to the reduced amount of hemoglobin inside the red blood cells, where the average weight of hemoglobin in red blood corpuscle in $\mathrm{MCH}$ Alcatel $15.78 \pm 0.31 \mathrm{Pg}$, while in Nokia amounted to $14.46 \pm 0.26 \mathrm{Pg}$, compared to the control group and that the average weight of hemoglobin by $16.28 \pm 0.28 \mathrm{Pg}$ (Table 3 ). Increased exposure time to 45 minutes appears the clear influence of the radiation from mobile phones (Alcatel and the Nokia on the swabs of blood, where the forms was completely normal, also the sizes of red blood cells differ from normal size it was greater than those seen in the two previous periods with clear ears between red blood cells, which suggests to lyses of many cells leading to a substantial short fall in the number of red blood cells as shown in Tables $\mathbf{1}$ and $\mathbf{3}$ that the average number was $8.33 \pm 0.441012 / \mathrm{L}$ when exposed to Alcatel while $8.07 \pm 0.791012 / \mathrm{L}$ when exposed to Nokia and compared to previous periods and the average number of control group was $9.71 \pm 0.34$ 1012/L. As noted in (Figure 4), the spread of atypical forms of red blood cells Poikilocytosis (Po), with irregular pigmentation of some red blood cells Anisochromia (An) and the obvious impact on the size of the red blood cells, with some red blood cells cleft Stomatocytosis (St) and appear in this type ascontaining a crack in the center appears as a concave mouth. the present result showed that the mobile phone Nokia has had a stronger effect on the blood, where a shortage in the intensity of coloring inside the red blood cells and appear pale due to lack of concentration of hemoglobin (Hypochromia, Hy), and this is confirmed as shown in Table 3, where a decrease in the average concentration of hemoglobin inside the red blood cell when exposed to Nokia $36.68 \pm 0.68 \mathrm{~g} / \mathrm{dL}$ for 45 minutes compared to the previous two exposure times. As noted in some cells of hemoglobin disorder where the cells take blue italic gray as a result of the accumulation of the stain within the hemoglobin and blood cells called here Polychromia any increase pigmentation of red blood cells as defined [24].

It was noted that the exposed animals for longer period up to 60 minutes which represents swab of the blood of mice that had been Alcatel appearance of varying red blood cells sizes (Anisocytosis). This type of cell appears in the cases of anemia, hemolytic [41] and there is also an increase in pigmentation of some of the pellets and the pellet knows in this case Polychromia. The present result showed that a large proportion of the red blood cells as spherocytes as well as the presence of large numbers of blood cells, which noted increase in pigmentation of the red blood cells as a result of the acquisition of hemoglobin with large amount of stain known as the p0lychromia and often These are cells larger than normal red blood cells, where we find that it was here $42.64 \pm 0.76 \mathrm{FL}$ if compared with control group, which has the size of the red blood cells $42.5 \pm 0.45 \mathrm{FL}$ also notes the existence of different and irregular in the form of red blood cells (Pokilocytosis) and represented here bearings take the form of a drop of Eye tears (Tear drop cells), and this type of cells may be an indicator of cancer of the blood and anemia [24].

In this part of the research animals were exposed to long periods ( long-term experiment) of time and that of mobile phones on both the above-mentioned unit (Alcatel, Nokia) for an hour and a half a day, every day without interruption and continue the exposure of three consecutive months. Many of the pathological changes of red blood cells were observed after exposure to the Alcatel and Nokia devices. The red blood cells with seriated wall were observed with different number of humps and other showed cover surround red blood cells from the outside, this shows red blood cells serrated with the edge, the cells called burr cells or called Echinocytes erythrocytes, Martin, et al. [42] confirmed that these abnormal form of red blood cells due to the presence of anemia or anemia caused by kidney failure.

From the current study that there was a change and a clear imbalance occurred in the forms and sizes of red blood cells and their contents when exposed to electromagnetic waves generated by mobile phones this may be attributed due to a malfunction [43] and a clear change in the form of the membrane that surrounds the primiparous red blood, it leads to an imbalance in the function of the membrane due to electromagnetic waves, Dudek [20] mentioned that the cell membrane of the globule is what gives it the flexibility necessary to make them pass more accurate capillaries as The control over the exchange of elements to and from inside the red cells and any defect in form and composition of the atmosphere due to external stimuli that lead to a difference in the composition and shape of the membrane, thereby hindering the establishment of this membrane natural cycle, which in turn leads to the emergence of some serious diseases. This is consistent with what was said by Ali [44] that the electromagnetic waves of exposure to human from mobile phones lead to damage and a clear influence on the cell walls, especially walls of red blood cells and cause an imbalance in blood enzymes. Scheffecter, et al. [8] proved a close relationship between exposure to a magnetic field 
and high and low blood pressure and proven laboratory experiments that the gene (genes), which turn out to be genes of cancer in the blood multiply much more quickly if exposed to radiation emitted from mobile phones more than 48 hours and the number of cells that died more than $20 \%$ of cells not exposed to any radiation (National Council for the Protection, 2002). Braune, et al. [7] found that the lymphocytes growing by numerical prolixferation thus cellular mutations happen after exposure to electromagnetic waves, this current search confirm that findings of an increase in the percentage of lymphocytes after exposure of animals to waves of mobile phone and a strengthening of the mobile phone .Yao, et al. [45] observed a change in the composition of hemoglobin inside red blood cells membrane which affects the physiological function of and capacity to transport oxygen, as observed decrease in hemoglobin concentration after exposure to electromagnetic waves. While there was an increase in the cell decomposition which affect the flow of potassium ions from red blood cells of rabbits that were exposed to electromagnetic waves, which indicates the strength of cells carry the blood of humans to high temperature and adaptability, however, while not tolerate blood cells rabbit this increase caused by heating and exposure to electromagnetic waves, which reported with many of the scientists and the actual impact of the hard electromagnetic waves is the effect of heat raises the temperature of the tissue [46]. This is consistent with Black \& Heynik [47] who found that did not caused changes, clear decomposition of the red blood cells and did not increase the temperature as well as the sensitivity of the white blood cells when exposed to electromagnetic waves. Stronati, et al. [48] reported that the lack of any damage to the cells of human blood or genetic mutations of blood when exposed to $50 \mathrm{~Hz}$ frequency or $60 \mathrm{~Hz}$ for 24 hours, while in some cases there may provoke the onset of these mutations.

\section{REFERENCES}

[1] K. Rekecho, "Electricity and Environmental Pollution, the Effect of Electromagnetic Fields on Health,” AL-Zad Company, Jeddah, 1999.

[2] M. E. Al-Rajhi, "Valuation of the Risks of Very Low Frequency and Non-Ionizing Electromagnetic Radiation Emitted by Electric Current of 50/60 Hz, Its Biological Effect, and Organization of Legislating Exposure Limites,” Riyadh College of Technology, Riyadh, 2006.

[3] Y. Djeridane, Y. Touitou and R. de Seze, "Influence of Electromagnetic Fields Emitted by GSM-900 Cellular Telephones on the Circadian Patterns of Gonadal, Adrenal and Pituitary Hormones in Men,” Radiation Research, Vol. 169, No. 3, 2008, pp. 337-343. doi:10.1667/RR0922.1

[4] V. K. Sud and G. S. Sekhon, "Blood Flow through the
Human Arterial System in the Presence of a Steady Magnetic Field," Physics in Medicine and Biology, Vol. 34, No. 7, 1989, p. 795. doi:10.1088/0031-9155/34/7/001

[5] A. Bortkiewicz, "A Study on the Biological Effects of Exposure Mobile-Phone Frequency EMF," Medical Profession, Vol. 52, No. 2, 2001, pp. 101-106.

[6] S. A. Al Sattar, "Mobile Phones and Electromagnetic Pollution,” Journal of Environmental Studies, Vol. 2, 2005, pp. 22-27.

[7] S. Braune, C. Wrocklage, J. Raczek, T. Gailus and C. Ludking, "Resting Blood Pressure in Chease during Exposures to a Radio-Frequency Electromagnetic Field," Lancet, Vol. 351, No. 9119, 1998, pp. 1857-1858. doi:10.1016/S0140-6736(98)24025-6

[8] K. Scheffecter, H. Lu, K. Norman, N. Van Nood, F. Munoz and A. Beaudet, "Spontaneous Skin Ulceration and Defective T Cell Function in Cd 18 Null Mice,” The Journal of Experimental Medicine, Vol. 188, No. 1, 2007, pp. 119-131.

[9] M. Karel, M. Jan and T. Hand, "Biological Effects of Electromagnetic Waves and Their Mechanism,” 1971. http://www.totalitaer.de/Waffen/englelectmagfieldlife.ht $\mathrm{m}$

[10] W. R. Adey, "Brain Tumor Incidence in Rats Chronically Exposed Digital Cellular Telephone Fields in an Initiation-Promotion Model," 18th Annual Bioelectromagnetics Society Meeting, Victoria, 9-14 June 1996, p. 18.

[11] G. J. Hyland, "Physics and Biology of Mobile Telephony,” Lancet, Vol. 356, No. 9244, 2000, pp. 1833-1836. doi:10.1016/S0140-6736(00)03243-8

[12] P. Michelozzi, A. Capon, U. Kirchmayer, et al., "Adult and Childhood Leukemia near a High-Power Radio Station in Rome, Italy,” American Journal of Epidemidoly, Vol. 155, No. 12, 2002, pp. 1096-1103. doi:10.1093/aje/155.12.1096

[13] L. G. Salford, A. Brun, K. Sturesson, J. L. Eberharott and B. R. R. Person, "Permeability of the Blood-Brain Barrier Induced by 915 MHZ Electromagnetic Radiation, Continuous Wave and Modulated at 8.16.50. and 200 HZ,” Medical Profession, Vol. 34, 1994, pp. 234-241.

[14] G. T. Liu, X. J. Wang, B. Q. Ai and L. G. Liu, "Numerical Study of Pulsatile Flow through a Tapered Artery with Stenosis," Chinese Journal of Physics, Vol. 42, No. 4, 2004, pp. 401-409.

[15] P. K. Mandal, “An Unsteady Analysis of Non-Newtonian Blood Flow through Tapered Arteries with a Stenosis," International Journal of Non-Linear Mechanics, Vol. 40, No. 1, 2005, pp. 151-164. doi:10.1016/j.ijnonlinmec.2004.07.007

[16] R. Bali and U. Awasthi, "Effect of Magnetic Field on the Resistance to Blood Flow through Stenotic Artery," Applied Mathematics and Computation, Vol. 188, No. 2, 2007, pp. 1635-1641. doi:10.1016/j.amc.2006.11.019

[17] G. Varshney, V. K. Katiyar and K. Sushil, "Effect of Magnetic Field on the Blood Flow in Artery Having Multiple Stenosis: A Numerical Study,” International Journal of Engineering, Science and Technology, Vol. 2, No. 2, 2012, pp. 67-82. 
[18] N. T. Kuipers, C. L. Sauder and C. A. Ray, "Influence of Static Magnetic Fields on Pain Perception and Sympathetic Nerve Activity in Humans," Journal of Applied Physiology, Vol. 102, No. 4, 2007, pp. 1410-1415. doi:10.1152/japplphysiol.00734.2006

[19] M. Turgeon, “Clinical Hematology,” Little Brown Company, New York, 1988.

[20] J. B. Maite, “Laboratory Medicine Hematology,” 5th Edition, Mosby Company, Saint Louis, 1977.

[21] R. W. Dudek, "High-Yield Histology," 2nd Edition, Lippincott Williams \& Willkins, Philadelphia, 2000.

[22] A. R. Fatayer, "Hematology (Theoretical and Practical) Culture Library House for Publication and Distribution,” Journal of Environmental Studies, Vol. 2, 2006, pp. 223229.

[23] R. G. D. Steel and J. H. Torrie, "Principles and Procedures of Statistics," 2nd Edition, McGraw Hill Book Company, New York, 1980.

[24] R. Soud, "Human and the Environment (Education Study of the Environment) Dar Al-Hamed for Publication and Distribution," Journal of Environmental Studies, Vol. 1, 2004, pp. 23-31.

[25] A. G. Althbyta, "Introduction of Haematology and Blood Diseases, Laboratory Diagnostic Methods,” King Fahd National Library, Riyadh, 2002.

[26] A. Al Shaer and H. I. E. Kaanan, "Haematology,” 1991.

[27] G. Clark, "Staining Procedures,” Lippincott Williams \& Willkins, Philadelphia, 1988.

[28] H. A. Zelly, "Do Not Harm from Them if We Avoided Risks: Equipment Hair Potential Health Problems,” Welcome to the magazine, San Francisco, 2007.

[29] B. S. Anderson and A. K. Tlenderson, "Cancer Incidence in Census tracts with Broadcasting Towers in Honolulu, Hawii,” State of Hawaii Department of Health, 1996.

[30] G. Maskarines, J. Cooper and L. Swygert, "Investigating of Increased Incidence in Childhood Leukemia near Radio Towers in Hawaii: Preliminary Observations," Journal of Environmental Pathology, Toxicology and Oncology, Vol. 13, No. 1, 1994, pp. 33-37.

[31] D. R. Mckenzie, Y, Yin and S. Morels, "Childhood Incidence of Acute Lymphoblastic Leukemia and Exposure to Broadcast Radiation in Sydney-A Second Look," Australian and New Zealand Journal of Public Health, Vol. 22, No. 3, 1998, pp. 360-367. doi:10.1111/j.1467-842X.1998.tb01392.x

[32] S. J. London, D. C. Thomas, J. D. Bowman, E. Sobel, T. C. Cheng and J. M. Peters, "Exposure to Residential Electric and Magnetic Field and Risk of Childhood Leukemia,” American Journal of Epidemiology, Vol. 134, No. 9, 1991, pp. 923-937.

[33] S. Takahashi, S. Inagume, Y. Cho, K. Imaida and T. Shirai, "Lack of Mutation Induction with Exposure to 1.5 $\mathrm{GHz}$ Electromagnetic near Fields Used for Cellular Phones in Brain of Big Blue Mice,” Cancer Research, Vol. 62, No. 7, 2002, pp. 1956-1960.
[34] K. Ikeda, Y. Shin-Mura, H. Mizoa, H. Yoshizawa and H. Roses, "No Effects of Extremely Low Frequency Magnetic Fields Found on Cytotoxic Activitites and Cytokine Production of Human Peripheral Blood Monocuclea Cells in Vitro," Bioelectromagnatic, Vol. 24, No. 1, 2003, pp. 21-31. doi:10.1002/bem.10062

[35] J. A. Dennis, C. R. Muirhead and J. R. Ennis, "Human Health and Exposures to Electromagnetic Radiation," National Radiation Protection Board Report, London, 1992.

[36] P. K. Verkasalo, E. Pukkala and M. Y. Hongisto, "Risk of Cancer in Finnish Children Living Close to Power Lines," British Medical Journal, Vol. 307, No. 6909, 1993, pp. 895-899. doi:10.1136/bmj.307.6909.895

[37] R. A. Kleinerman, W. T. Kaune, E. F. Hatch, S. Wacholer, M. S. Linet, et al., "Are Children Living near High Voltage Power Lines at Increased Risk of Acuto Lymphoblastic Leukemra,” American Journal of Epidemiology, Vol. 151, No. 5, 2000, pp. 512-515. doi:10.1093/oxfordjournals.aje.a010237

[38] E. B. Willett, P. A. Mckneey, N. T. Fear, et al., "Occupational and Acute Leukemia: Analysis of a Case-Control Study," Occupational and Environmental Medicine, Vol. 60, 2003, pp. 577-583. doi:10.1136/oem.60.8.577

[39] H. Sayed, "Atlas of Descriptive Anatomy: Cell and Tissue Biology of Fetuses,” Arab Book Library House, Jeddah, 2005

[40] H. Carr and B. F. Rodek, "Clinical Hematology Atlas," Saunders Company, Philadelphia, 1999.

[41] A. V. Hoffbrand, J. E. Pettit and P. A. Moss, "Hematology," 4th Edition, G. Canale \& C. S.p.A. Company, Jeddah, 2002.

[42] S. Martin, et al., "Clinical Hematology," 2nd Edition, Lippincott Williams \& Willkins, Philadelphia, 1998.

[43] R. Seza, et al., "Radio Cellular Telephones Do Not Disturb the Secrttion of Antepituitay Hormones in Humans," Bioelectromagntics, Vol. 19, No. 3, 1998, pp. 444-449.

[44] F. Ali, "Choose between Using a Mobile Phone Frequently Lead to Premature Aging,” Journal of Environmental Studies, Vol. 1, No. 2, 2006, pp. 132-137.

[45] C. Yao, X. Li and Y. Xiong, "Instant Effects of Radiofrequency Electromagnetic Wave on Hemoglobin in Single Living Intact Red Blood Cell,” Chinese Chermical Letters, Vol. 16, No. 8, 2005, pp. 1121-1124.

[46] WHO, "Wireless Electric Devices and Health,” 2006.

[47] D. Black and L. N. Heynik, "Radiofrequency (RF) Effects on Blood Cells, Cardiac, Endocrine and Immunologicalfunctions,” Biolelectromanetics, Vol. 6, 2003, pp. 51875195

[48] L. Stronati, A. Testa, P. Villanai and E. Cordelli, “Absence of Genotoxicity in Human Blood Cells Exposed to $50 \mathrm{~Hz}$ Magnetic Fields as Assessed by Comet Assay, Chromosome Aberration, Micronucles and Sister Chromatic Exchange Analyses,” Bioelectromagnetic, Vol. 25, No. 1, 2004, pp. 41-48. doi:10.1002/bem.10141 